\title{
Aerosol spectral optical depths and size characteristics at a coastal industrial location in India - effect of synoptic and mesoscale weather
}

\author{
K. Niranjan, B. Malleswara Rao, Auromeet Saha, and K.S.R. Murty \\ Department of Physics, Andhra University, Visakhapatnam 530 003, India
}

Received: 1 April 2003 - Revised: 18 October 2003 - Accepted: 29 October 2003 - Published: 14 June 2004

\begin{abstract}
The aerosol spectral optical depths at ten discrete channels in the visible and near IR bands, obtained from a ground-based passive multi-wavelength solar radiometer at a coastal industrial location, Visakhapatnam, on the east coast of India, are used to study the response of the aerosol optical properties and size distributions to the changes in atmospheric humidity, wind speed and direction. It is observed that during high humidity conditions, the spectral optical depths show about $30 \%$ higher growth factors, and the size distributions show the generation of a typical new mode around 0.4 microns. The surface wind speed and direction also indicate the formation of new particles when the humid marine air mass interacts with the industrial air mass. This is interpreted in terms of new particle formation and subsequent particle growth by condensation and self-coagulation. The results obtained on the surface-size segregated aerosol mass distribution from a co-located Quartz Crystal Microbalance during different humidity conditions also show a large mass increase in the sub-micron size range with an increase in atmospheric humidity, indicating new particle formation at the sub-micron size range.
\end{abstract}

Key words. atmospheric compositon and chemistry (aerosols and particles); synoptic scale meteorology (meteorology and atmospheric dynamics)

\section{Introduction}

Aerosol optical depth is an important parameter that characterizes the integrated extinction of solar radiation suffered in its transit through the atmosphere. Characterization of atmospheric aerosol physical properties at as many locations over the globe as possible is important in climate change studies. Comprehensive studies investigating the temporal and spatial relations of the aerosol spectral optical depths and size characteristics to the synoptic air mass and the surface anthro-

Correspondence to: K. Niranjan

(niranjankandula@hotmail.com) pogenic features is important to understand the mechanisms which define the optical state of the atmosphere. Assessing the long-term variations in the atmospheric aerosol physical properties, at different locations, is essential to reduce the overall uncertainty in the calculation of climate forcing by aerosols, to be able to provide a prognostic analysis of the future radiative forcing and climate response. Emerging ground-based aerosol climatology on the Aerosol Optical Depths (AOD) for different sites of AERONET was reported by Holben et al. (2001). Michalsky et al. (2001) reported that multi-year measurements of aerosol optical depths from three sites indicate similar seasonal and interannual changes, but with notable differences in the magnitude of aerosol optical depths. Parameswaran et al. (1998) have reported an increasing trend in aerosol optical depths over a coastal location in India during 1989-1994 and that this increase is not only confined to the mixing region, but also to higher altitudes. Several groups around the globe are working to accurately characterize the atmospheric aerosol system over different locations, to be able to provide precise information for the development of a global aerosol model. This demands a comprehensive study of the physical, chemical and radiative properties of the atmospheric aerosols under weather conditions influenced by different air mass types. The optical parameters show a wide variability depending on the air mass conditions under which the measurements are made (von Hoyningen Huene and Raabe, 1987; Gulyaev et al., 1990).

O'Dowd and Smith, 1993 reported that aerosols associated with anthropogenically influenced air masses over the Northeast Atlantic contained typically $80 \%$ sulphate particles, the remaining being soot and sea salt, while for arctic air masses, the contribution of sulphate was $60 \%$ due to a low concentration of sea salt which was dependent on wind speed. For situations with clean maritime air mass, sulphate aerosol accounted for less than $25 \%$ and the remaining consisted of predominant sea salt particles at all size ranges. The optical properties of continental and maritime air masses differ significantly, and it is relevant to apply the air mass 
type classification for the analyses and discrimination of atmospheric aerosol optical properties (Smirnov et al., 1995). Von Hoyningen Huene and Wendiseh (1994) reported that maritime air masses have low values of size index $\alpha$, while optical conditions formed with urban-industrial aerosol accumulated under the inversion layer show a size index of about 0.7 . The diurnal, seasonal and annual variations in the ground-based observations of the aerosol optical properties must be analyzed in the context of the prevailing synoptic conditions. The maritime air mass has significant dependence on wind velocity. Analyses of aerosol optical depth as a function of relative humidity in real environments resulted in highly variable reports and in some cases the efforts were statistically inconclusive (for example, Smirnov et al., 1995). Saxena et al. (1995), from analyses of data from typical non-urban and urban locations, reported that the aggregate hygroscopic properties of inorganic particles are altered substantially when organics are also present and that the alteration could be positive or negative depending on the location.

Simple analytical model studies of Khvorostyanov and Curry (1999) suggested that the aerosol size spectra are different in the three different humidity regimes, namely moderate, high humidity, but sub-saturation, and interstitial cloud aerosol and that the transition between these regimes is not smooth.

In a coastal and highly industrial location, it is difficult to interpret the column integrated optical properties of the atmospheric aerosols due to the mixing of two completely different air masses, namely continental and maritime, which could lead to the formation of new types of aerosols with completely different optical, physical and chemical properties. Analyses as a function of synoptic air mass, however, could lead to a reasonable understanding of the various features observed under different conditions. In this paper, the various features of aerosol optical depths observed at Visakhapatnam, a coastal industrial location on the east coast of India obtained using a ground-based multi-wavelength solar radiometer for a period of about 10 years, are reported. Support of the size segregated aerosol mass distribution obtained using a co-located Quartz Crystal Microbalance $(\mathrm{QCM})$ is given in interpreting the column-integrated physical properties. The observing site has an industrial area in the southwest and is very close to the sea coast $(500 \mathrm{~m}$ away). The city's industrial belt consists of a Steel plant, fertilizer, polymer, zinc industries and an oil refinery. During winter season winds are north-northeasterly with a speed of $7 \mathrm{~km} / \mathrm{h}$, while the temperature and humidity are $23^{\circ} \mathrm{C}$ and $75 \%$, respectively. The total rainfall in this season is about $6 \mathrm{~cm}$. During summer the winds are southwesterly with wind speeds in the range of $16 \mathrm{~km} / \mathrm{h}$, while the temperature is around $32^{\circ} \mathrm{C}$ and a humidity of around $80 \%$. The station experiences two spells of rainfall: during the southwest monsoon (June to August) and again during the northeast monsoon (October and November). The total rainfall during the season is about $40 \mathrm{~cm}$. In the upwind direction of the northeast, the industrial belts of Kolkatta lying north of the location on the east coast of India consist of jute, engineering, chemicals and petrochemicals, paper, leather, steel, ferroalloys industries, while Bhubaneswar and adjoining areas in the state of Orissa have aluminum, iron and steel, cement, fertilizer, paper and sugar, petrochemical complex in Paradeep. However, these two industrial belts of Kolkatta and Bhubaneswar are more than $600 \mathrm{~km}$ away towards the north from the observing location.

\section{Instrumentation and data}

A multi-wavelength solar radiometer is in operation at Visakhapatnam since December 1987. It is a passive radiometer operating at 10 discrete wavelengths in the visible and near IR bands between $380 \mathrm{~nm}$ to $1025 \mathrm{~nm}$. The total optical depths evaluated from the flux measurements are corrected for Rayleigh optical depth from the known neutral air profiles from this station (Niranjan et al., 1997). Eight of the 10 wavelengths fall outside any strong molecular absorption bands, except the $600 \mathrm{~nm}$, which falls in the Chappuis band of Ozone absorption and $940 \mathrm{~nm}$ that falls at the $\rho \sigma \tau$ band of water vapour absorption. Measurements at these two wavelengths are used to evaluate the column content of ozone and water vapour (Niranjan and Ramesh Babu, 1993; Satheesh and Moorthy, 1996 and Nair and Moorthy, 1998), which are used to correct for the molecular absorption at the adjacent wavelengths. Aerosol optical depths evaluated after correcting for the Rayleigh component and molecular absorption are used to study the spectral and temporal characteristics. From the spectral optical depths, the column integrated number density size distribution of the coastal urban aerosols is obtained by constrained linear inversion of Mie integral equation

$\tau_{\rho \lambda}=\int_{r_{a}}^{r_{b}} \pi r^{2} Q_{\mathrm{ext}}(m, r, \lambda) n_{c}(r) d r$,

where $Q_{\text {ext }}$ is the aerosol extinction efficiency factor, which depends on the refractive index $(m)$, radius $(r)$ and the wavelength of the incident radiation $(\lambda) . n_{c}(r)$ is the columnar size distribution function of aerosols (number of aerosols in a vertical column of unit cross section in a small radius range $d r$ centered around $r$ ), and $r_{a}$ and $r_{b}$ are the lower and upper radii limits for integration. The above equation is solved for $n_{c}(r)$ following the iterative inversion procedure described by King et al. (1978) and King (1982). The upper and lower radii limits $r_{a}$ and $r_{b}$ are taken as 0.1 and $5.0 \mu \mathrm{m}$, respectively. Considering the aerosol sources around Visakhapatnam, the refractive indices are taken from Shettle and Fenn (1979) for an aerosol composition of 20\% background, 38\% anthropogenic, $40 \%$ water soluble sea slats and $2 \%$ soot.

A California Measurements Inc. model Quartz Crystal Microbalance (QCM) Cascade Impactor System with 10 size cut-off stages ranging from 0.05 to $25 \mu \mathrm{m}(25,12.5,06.4$, $3.2,1.6,0.8,0.4,0.2,0.1 \mu \mathrm{m}$, respectively) is co-located with the existing MWR at Visakhapatnam. The instrument 


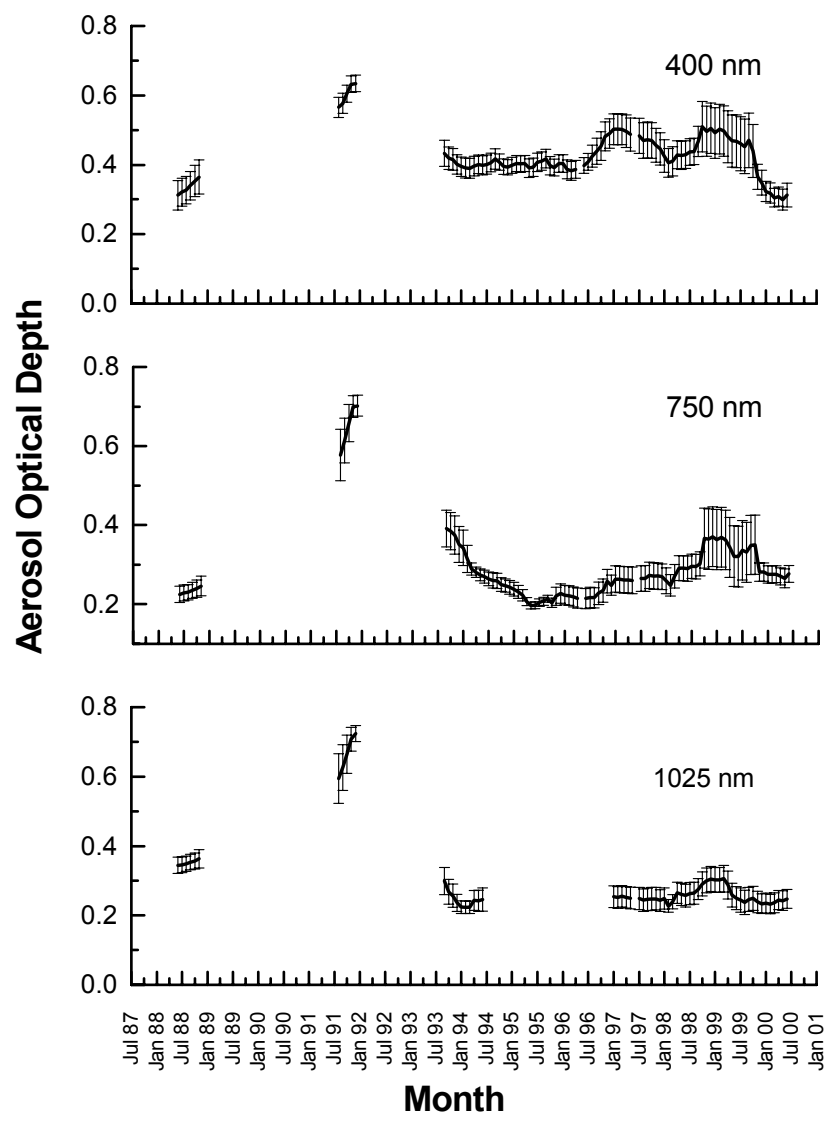

Fig. 1. Temporal variation of the 13-point running mean aerosol optical depth at $400 \mathrm{~nm}, 750 \mathrm{~nm}$ and $1025 \mathrm{~nm}$. The vertical bars represent the standard deviation of the mean.

utilizes an inertial impaction principle to segregate and collect particles by size and oscillating quartz crystal mass sensors in each impactor stage to report particle mass collection. The size segregated mass distribution is used to evaluate the surface aerosol size distribution.

\section{General features of aerosol optical depths and size characteristics over Visakhapatnam}

The aerosol spectral optical depths at Visakhapatnam show a seasonal dependence with summer maximum and winter minimum. The spectral slope $\alpha$ (Angstrom parameter) is around 1.1 in winter and early summer, while, it is quite low during summer (May/June) when the onset of a sea breeze is more probable and is associated with a maritime air mass (Niranjan et al., 1997). Figure 1 shows the 13-point running mean variation of aerosol spectral optical depths along with the standard deviations (vertical bars) at three typical wavelengths $400 \mathrm{~nm}, 750 \mathrm{~nm}$ and $1025 \mathrm{~nm}$ during July 1987 to January 2001. The Langley intercept is continuously monitored for all the days of observation, as a check on the system calibration and it is found to be constant throughout the period of observation with a standard deviation varying between 1-4\% at different wavelengths. During 1993-1995,
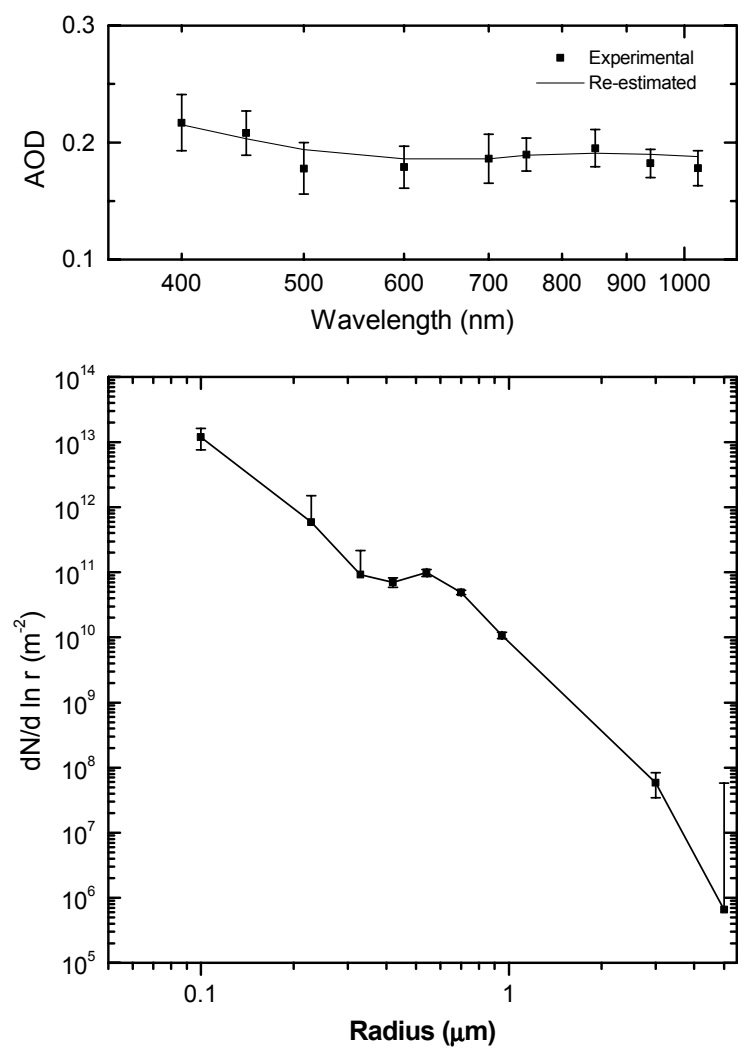

Fig. 2. Typical aerosol columnar number density - size distribution at Visakhapatnam (bottom panel). The top panel shows the experimental data (points with standard deviation) used in the inversion and re-estimated aerosol optical depths (solid line) retrieved from the obtained size distribution.

the column optical depths are affected by the Pinatubo volcanic activity and hence, the 13-point running means at those five points show significantly higher values. It may be noted that the running mean for a month is considered only if continuous 13-month data, i.e. 6 months before and 6 months after the month, are available. Therefore, the data show some gaps, although data are available during that particular year. During 1990 and 1991, there was some discontinuity in the data and hence 13-point means could not be evaluated for all the months. The 13-point running means are shown with the purpose of eliminating the seasonal trends. It may be seen that at shorter wavelength of $400 \mathrm{~nm}$, the aerosol spectral optical depths are reasonably stable until mid 1996 and thereafter we observed two distinct peaks centered around 1997 and 1999 with a trough in 1998 . This trend with two peaks is seen at $400,450,500$ and $600 \mathrm{~nm}$. However, at longer wavelengths $(750 \mathrm{~nm})$ a peak is seen only in 1999 and the AODs at other wavelengths show a tendency for increased values around 1999, even though the percent increase from the mean long-term trend is very small.

The column integrated aerosol number density size distributions obtained by the inversion of the aerosol spectral optical depths which show a bi-modal distribution is shown in Fig. 2, with a primary mode around $0.1 \mu \mathrm{m}$ and a secondary 


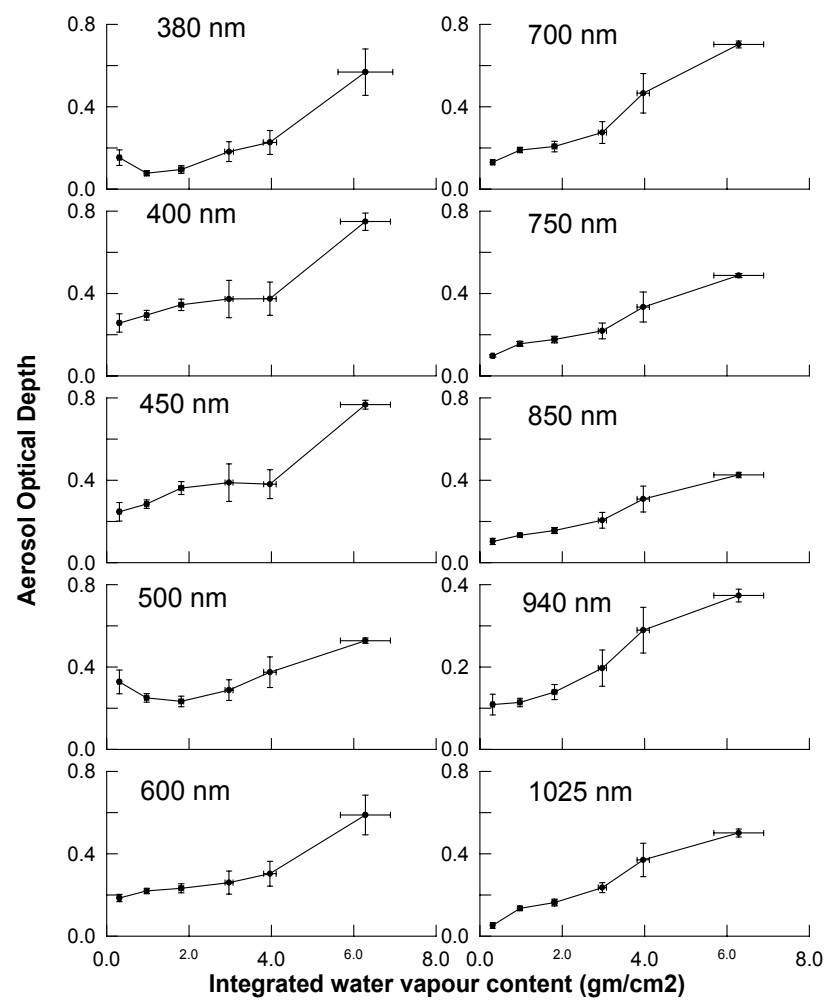

Fig. 3. Variation of mean aerosol optical depths at 10 different wavelengths as a function of columnar atmospheric water vapour content.

mode around $0.8 \mu \mathrm{m}$. The primary mode reflects the presence of the gas to particle conversion processes characteristic of industrial environment and the secondary mode indicates the presence of sea spray aerosols as a result of the bulk-toparticle conversion on the sea surface (Niranjan et al., 2000). Whenever inversion of aerosol size distribution is attempted, the aerosol spectral optical depths are re-estimated from derived size distributions and compared with the actual measured values used in the inversion algorithm (shown in the top panel of Fig. 2). The size distribution is considered only if the measured and retrieved optical depths match within the standard deviation of the measurements. The size distribution indicates that the sub-micron aerosol concentration dominates with an $89 \%$ share of the integrated column content, while the super micron aerosol share is about $11 \%$.

\section{Effect of atmospheric humidity on the aerosol size dis- tributions}

In Fig. 3 the variations of aerosol optical depths as a function of the column integrated water vapour content at all 10 wavelengths, are shown. Since the AODs refer to column integrated features, the column integrated water vapour is considered and the surface relative humidity RH is not considered. The horizontal bars represent the variance in the integrated water vapour content around the mean, while the ver-

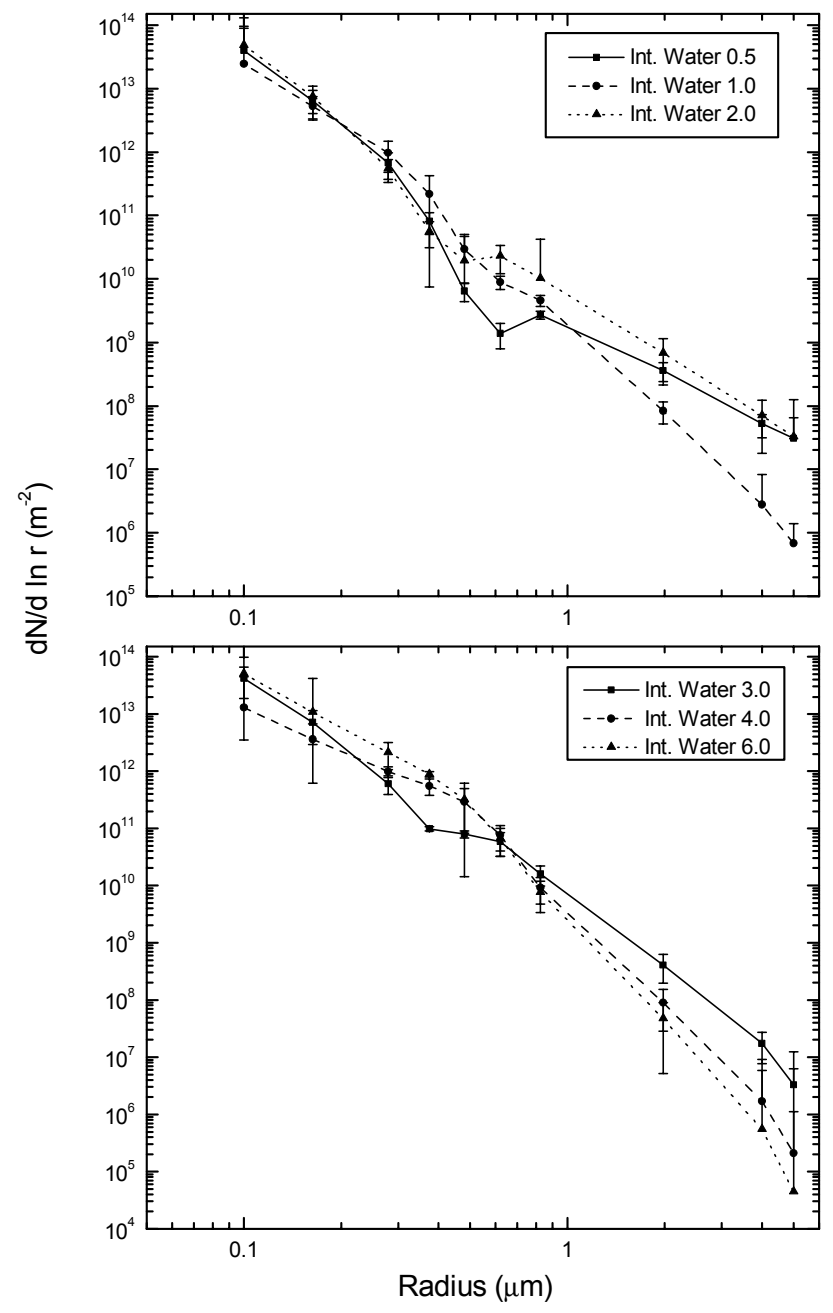

Fig. 4. Column integrated aerosol number density size distributions for different conditions of atmospheric humidity in terms of integrated water vapour content.

tical bars represent the standard deviation around the mean AOD. It may be seen that the AODs show the usual hygroscopic growth factors. But the growth factors seen here are higher at shorter wavelengths than those reported earlier (Boucher and Anderson, 1995; Nair and Moorthy, 1998, Im et al., 2001). Secondly, it may be seen that the growth factors at the shorter wavelengths of 400 and $450 \mathrm{~nm}$ are higher at high humidity levels after $4.0 \mathrm{~g} / \mathrm{cm}^{2}$. At the intermediate wavelengths (500 and $600 \mathrm{~nm}$ ), however, they are moderate, while at $750 \mathrm{~nm}$ and $940 \mathrm{~nm}$, again the growth factors are higher.

In Fig. 4 the column integrated number density - size distributions at different humidity levels obtained from the inversion of AODs are shown. Initially, the size distribution shows usual bimodal distribution at low humidity levels $\left(0.5 \mathrm{~g} / \mathrm{cm}^{2}\right)$. For an initial increase of column water vapour content, particle population from sizes $0.3 \mu \mathrm{m}$ and above increase. For a further increase in column water vapour content $\left(2.0 \mathrm{~g} / \mathrm{cm}^{2}\right)$, a distinct secondary mode appears at $0.4 \mu \mathrm{m}$ and 

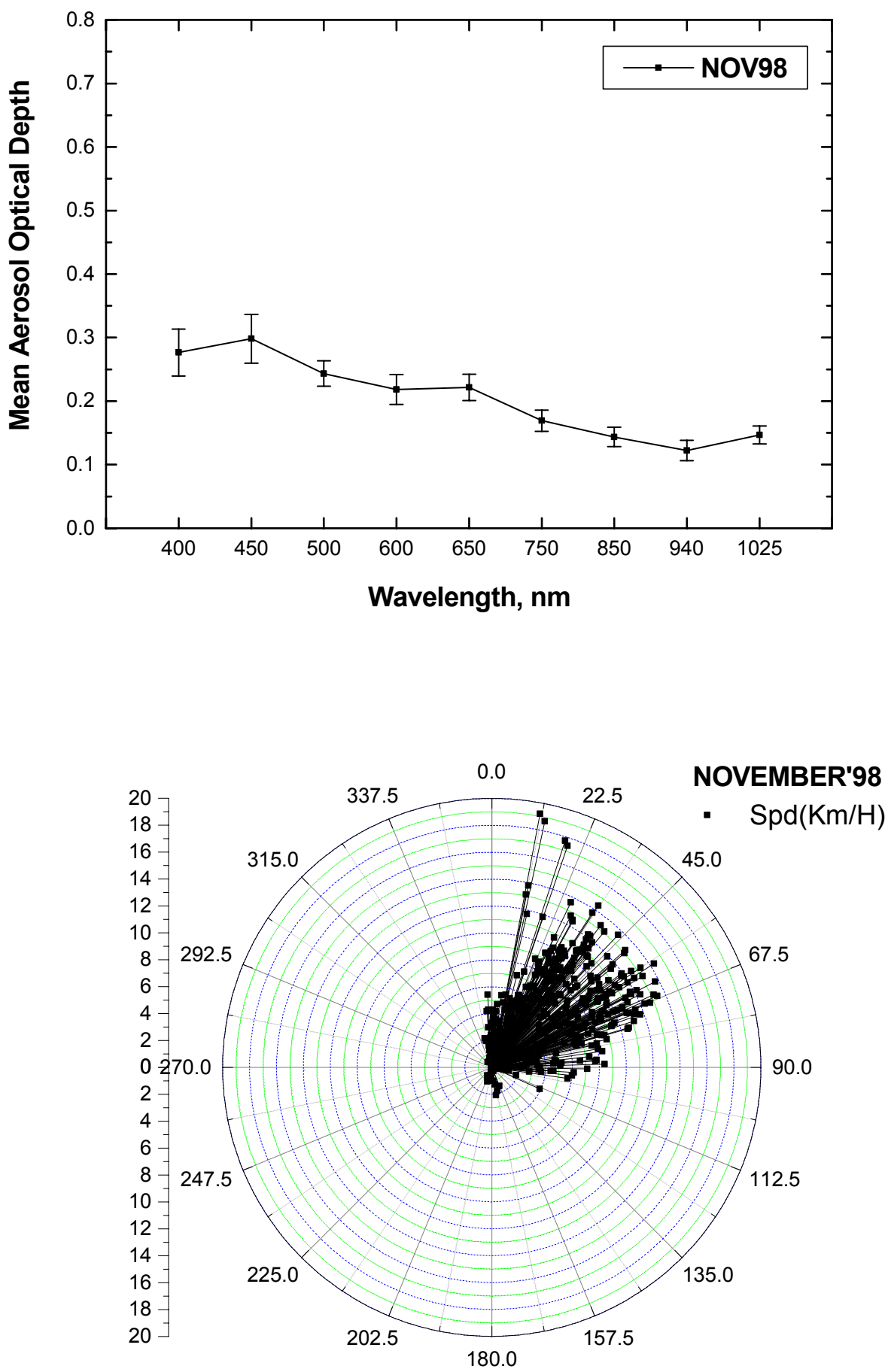

Fig. 5. Mean spectral variation of aerosol optical depth during a typical winter month (November 1998). The bottom panel shows the hourly mean wind speed and direction on the days considered in evaluating the mean AOD shown in the top panel.

the usual secondary mode between $0.7-0.8 \mu \mathrm{m}$ is buried in the new mode at $0.4 \mu \mathrm{m}$. When the column water vapour content is around $6.0 \mathrm{~g} / \mathrm{cm}^{2}$, a decrease in number density at the large particle size ( $2 \mu \mathrm{m}$ and above) is seen (please see the bottom panel of Fig. 4).

\section{Effect of surface wind on the aerosol properties}

Aerosol optical depths and their wavelength dependence are strongly influenced by air mass sources, which are dependent on the season (Pinker et al., 1997). In a coastal environment, mesoscale processes such as a land/sea breeze play an important role in determining the air mass characteristics (Keen and Lyons, 1978, Moorthy et al., 1997). However, a 

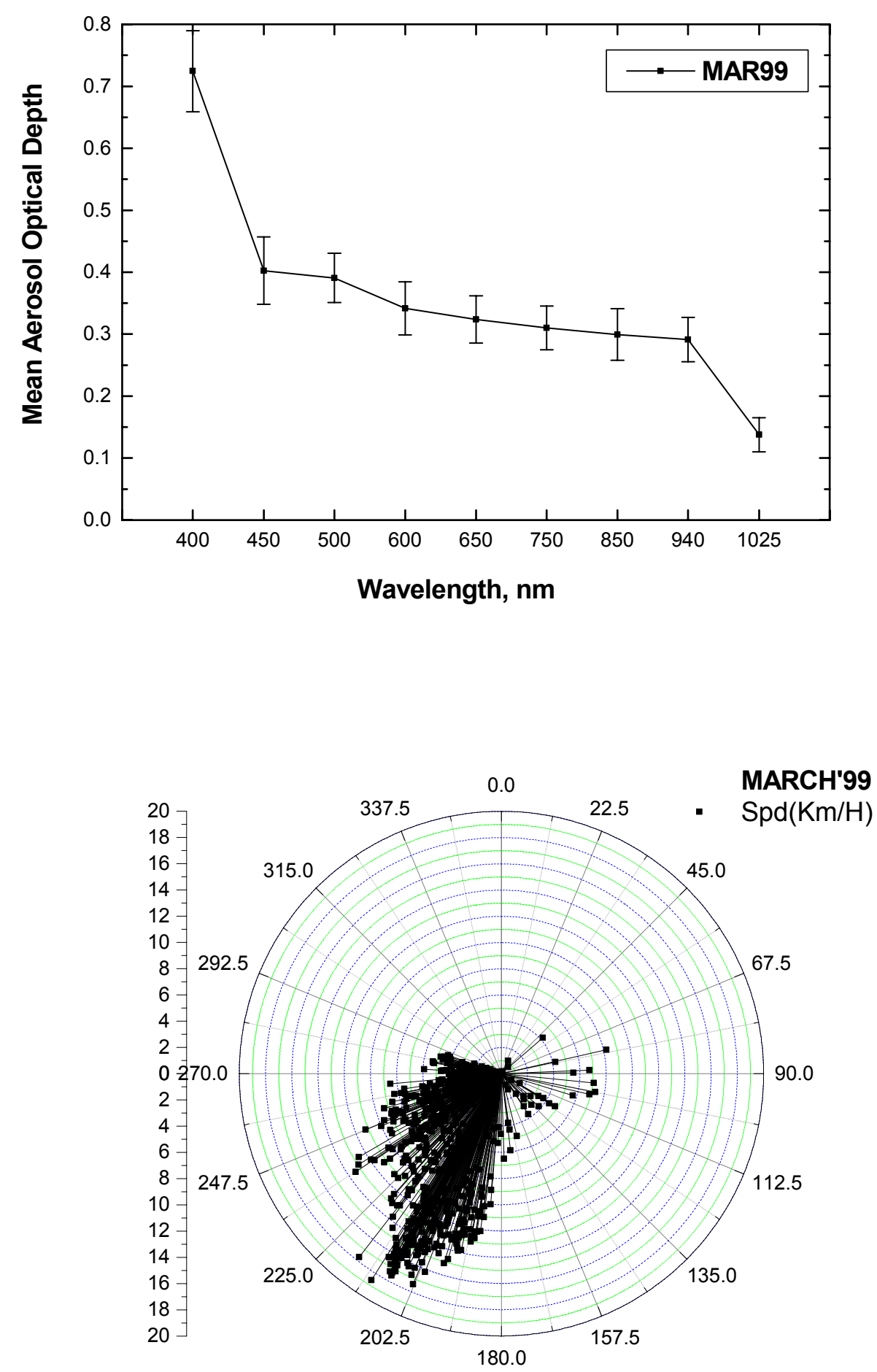

Fig. 6. Same as Fig. 5 for March 1999 when the wind is predominantly south/southwest.

priori estimates of air mass based on synoptical identification alone can yield useful results without the necessity of carrying out the back trajectory analysis (Smirnov et al., 1994). It is observed that at this location the surface wind speed and direction determine the characteristics of the air mass. If the wind is from the NE, as in the case of winter, the air mass reflects totally background aerosol properties, and the opti- cal depths show near Junge spectral properties as shown in Fig. 5. The top panel shows the mean spectral variation of the AOD during that month, while the bottom panel shows the mean wind speed and direction for the days considered in the study. However, during the summer, the wind is predominantly from the south/southwest. In Fig. 6 the spectral variation of aerosol optical depths are shown when the wind 


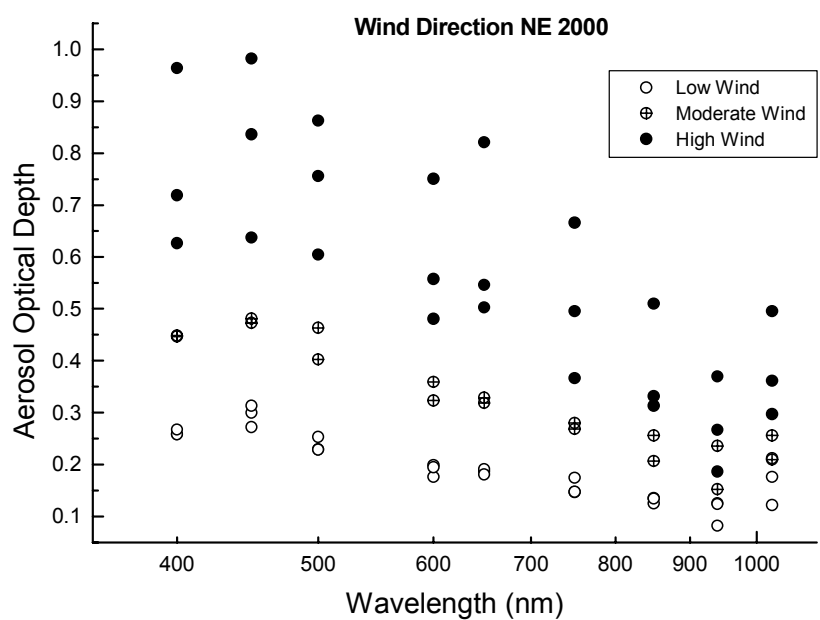

Fig. 7. Spectral variation of aerosol optical depths for different northeast (NE) wind conditions.

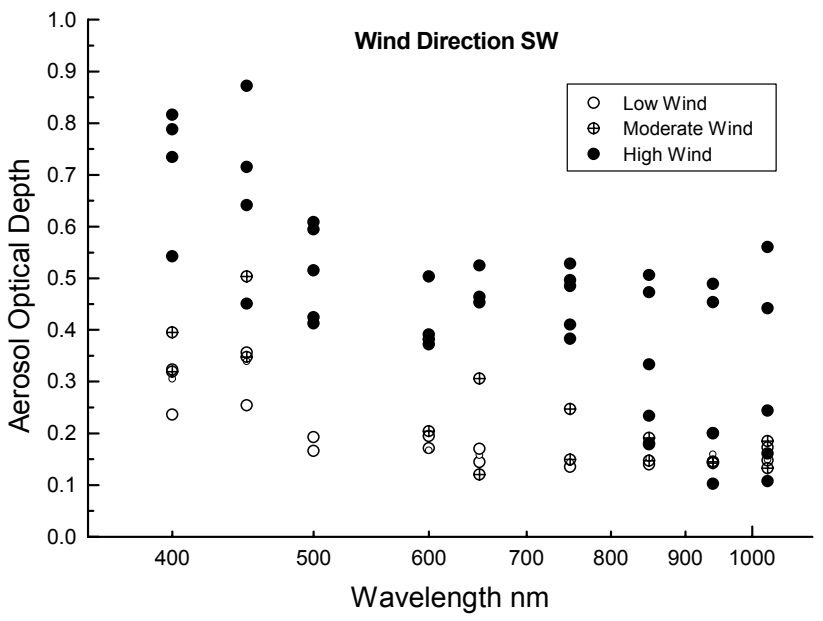

Fig. 8. Same as Fig. 7 for southwest wind condition.

is southwest, where high optical depths are seen at shorter wavelengths. The wind speed plays an important role in this case (the coastal urban nature of the site) due to the inland penetration of the marine air mass during high wind speed conditions. In such cases the marine air mass interacts with the air mass coming from the industrial establishments. To make a qualitative study of such features, we have separated the two cases, namely the NE wind condition and the S-SW wind conditions, and made a characteristic study on the effect of the wind speed on the aerosol spectral optical depths and size characteristics. Cases with wind speeds in the range of $<8 \mathrm{~km} / \mathrm{h}$ are classified as a low wind condition, $8-12 \mathrm{~km} / \mathrm{h}$ as a moderate wind condition and winds with $>16 \mathrm{~km} / \mathrm{h}$ as a high wind speed condition.

In Fig. 7 the spectral variation of aerosol optical depths on a few typical days with different wind speeds during the winter of 1998 are shown when the wind direction is from the NE. It may be seen that during the low wind speed con-

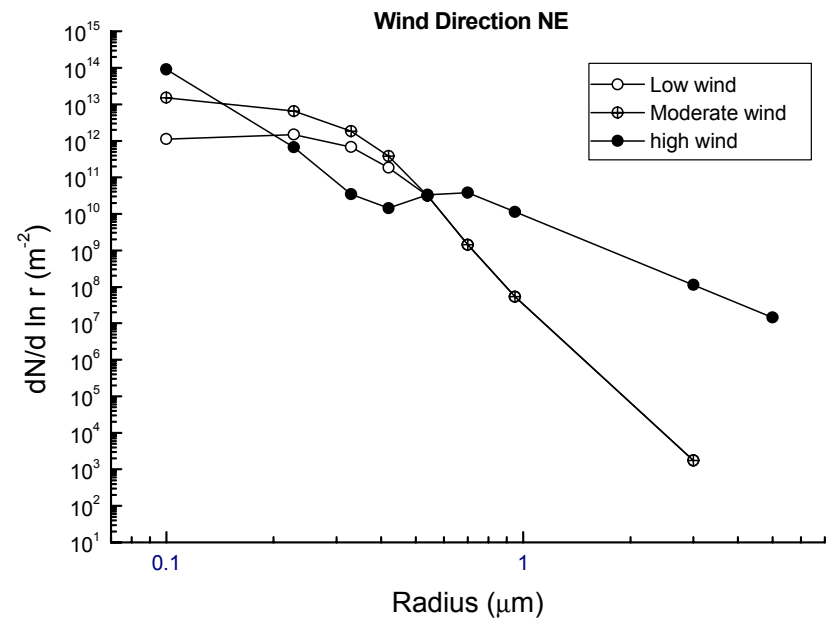

Fig. 9. Column integrated aerosol number density size distributions for northeast (NE) wind conditions.

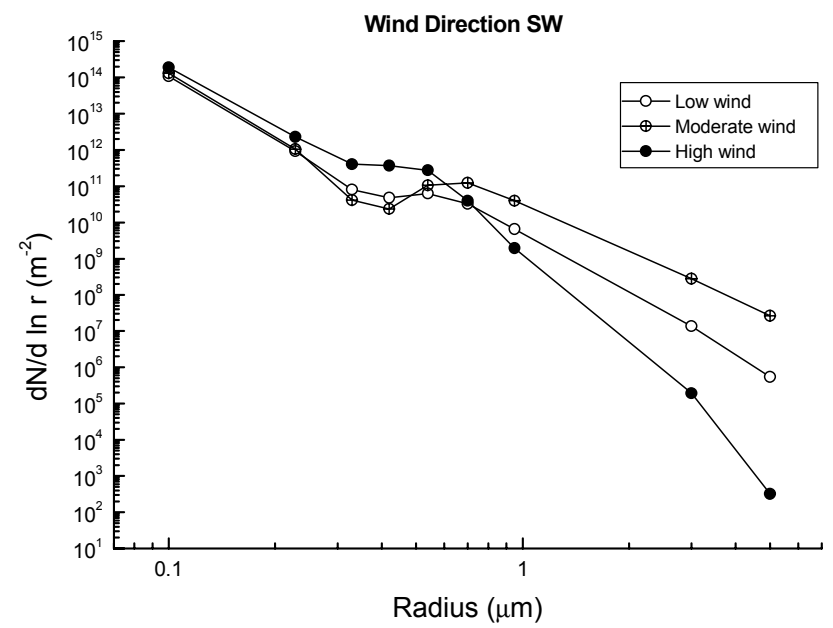

Fig. 10. Same as Fig. 9 for southwest wind condition.

ditions (open circles), the spectral characteristics show near background features. As the wind speed increases, the increase in spectral optical depths at shorter wavelengths is relatively higher but the spectral slope is still retained. In contrast when the wind is from S-SE the increase in AOD is steady at all wavelengths (Fig. 8) and the AODs at the mid wavelength band are equally sensitive to the increase in the surface wind speed. It may be seen that the spectral optical depths are higher than those compared to the condition with NE winds.

In Fig. 9 the column integrated aerosol number density size distribution profiles for various wind conditions are shown viz., low, moderate and high for the NE wind condition. It may be seen that when the wind speed is low and moderate, the aerosol density shows a distribution reflecting a combination of background and industrial particulate loading with a single prominent mode in the small particle region. But when the wind speeds are higher $(>16 \mathrm{~km} / \mathrm{h})$ the 


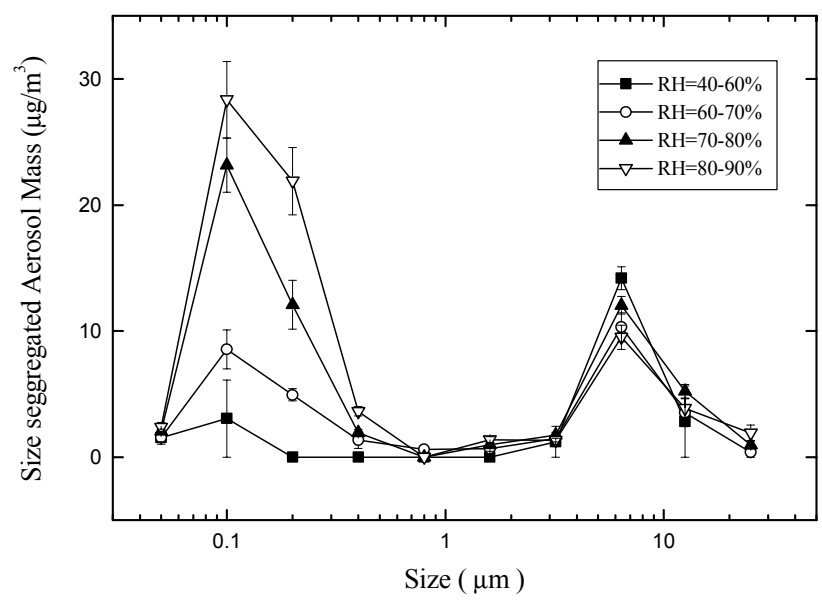

Fig. 11. Size segregated surface aerosol mass distribution obtained with a QCM system for different surface humidity conditions in the ten cut-off size ranges of the QCM.

aerosol size distributions show a bi-modal distribution with a secondary mode around $0.8 \mu \mathrm{m}$. This shows the presence of the sea salt aerosol, being brought in by the high-speed winds from the sea in the northeastern region of the observing location. This occurs only during high-speed NE wind conditions, as the seacoast is a little farther in the NE direction.

In Fig. 10 the column integrated aerosol number density size distributions during the SW wind conditions are shown. During low wind conditions, the size characteristics show a bi-modal distribution, even during low SW wind conditions. As wind speed increases, the particle concentration at mid particle range increases. For a further increase in the wind speeds, that is when the wind speeds are high, a distinct new mode appears around $0.4 \mu \mathrm{m}$ and the usual secondary mode is buried under this broad mode around $0.4 \mu \mathrm{m}$. Thus, during S-SW wind conditions, when the wind is moderate to high, particle population in the mid-size range increases as the coast is $500 \mathrm{~m}$ away from the observing location.

\section{Discussion}

The long-term database shown in Fig. 1 indicates significantly high values in aerosol spectral optical depths during 1997 and 1999. Moorthy et al. (2001), based on the NCEP wind data, as well as meteorological reanalysis, have shown that the when the spectral optical depths were close to the mean values, as in 1998, the Inter-tropical convergence zone (ITCZ), in general, has been far more south than in 1997 and 1999. In 1999, the ITCZ was situated just south of the equator. Since the convergence of winds from the continental and pristine oceanic regions takes place around the ITCZ, the resultant updraft prevents the aerosols from spreading far south of it and hence, the aerosols are confined to a smaller spatial region in these years, showing up as a distinct peak. This is more pronounced at shorter wavelengths as the larger particle sediment at a faster rate. Secondly it was observed that during 1999, an anti-cyclonic circulation was present (Jha and Krishnamurthy, 1999) that caused a trapping of aerosols and led to a further increase in the optical depths.

The response of the aerosol physical properties to an increase in the atmospheric humidity shows a peculiar behaviour at Visakhapatnam, with higher growth factors in aerosol optical depths and the generation of a distinct mode at $0.4 \mu \mathrm{m}$ in the column integrated number density size distributions. Depending on the aerosol composition, the aerosol extinction cross section may vary differently in the humidity range of $30 \%$ to $90 \%$ (Kasten, 1969; Fitzerald et al., 1982, Hegg et al., 1996). The light scattering of aerosol is strongly dependent on the $\mathrm{RH}$ at which it is measured, due to the hygroscopic nature of most of the aerosols. The hygroscopic growth curves are generally described in the form of $\sigma_{s p}$ (total scattering coefficient) as a function of RH. The hygroscopic growth factor, the ratio of $\sigma_{s p}(\mathrm{RH}=80 \%)$ to $\sigma_{s p}(\mathrm{RH}=30 \%)$, was calculated to be 1.61 for polluted continental, 1.61 for marine and 1.59 for continental aerosols (Im et al., 2001). Boucher and Anderson (1995) calculated the effective $\mathrm{RH}$ factor, defined as the ratio of radiative forcing by a hydrated aerosol using RH computed by a general circulation model and climate forcing computed for a constant $\mathrm{RH}$ value of $30 \%$, to be between 1.19 and 1.71 . However, the present studies indicate growth factors that are 30-35\% above the reported growth factors and are different at different wavelengths. Boucher and Anderson (1995) reported that the value of the hygroscopic growth factor decreases as the particle diameter increases, i.e. the smaller particles are more sensitive to increasing humidity. The humidity effect at such a coastal industrial location is more complex due to the interaction of the industrial gas phase reaction products abundant in an urban location with the humid marine air mass. It was reported that in the marine boundary layer, an increase in the wetness of the atmosphere would accelerate new particle formation due to gas to particle conversion and nucleation, particularly when it interacts with gas phase reaction products. Formation of new particles by nucleation often occurs in the marine and coastal atmosphere (Covert et al., 1992). It is known that nucleation tends to occur in air masses where sulfuric acid relative acidity is elevated (Clarke et al., 1998, Weber et al., 1999). Nucleation events have been observed at the coast in Mace Head in Ireland during on-shore flow (Grenfell et al., 1999, Mc Govern et al., 1996). In the present case, either when humidity is high or when there is an interaction of marine air mass with the industrial air mass, due to the abundance of gas phase reaction products and the resultant elevation of acidity levels, new particle formation seems to be accelerated by nucleation. Once nucleation occurs, new particles grow by condensation and self-coagulation until the particles reach a diameter of the order of the mean free path of the condensing molecule. Although under tropospheric background conditions, particles initially formed by nucleation take a longer time to grow, under polluted urban type conditions growth occurs quite rapidly because of the strong supply of condensable material from homogeneous 
gas phase reactions (Raes et al., 1995). Secondly, when the marine air mass penetrates inland, the production of submicron aerosols by the gas to particle conversion process is accelerated due to the reduction in temperature, which has the effect of reducing the species equilibrium vapour pressure, resulting in a thermodynamic driving force for condensation. Thus, the new mode must have been generated by new particle formation and their subsequent growth in the humid marine environment. The growth factors as a function of water vapour show $30 \%$ higher values compared to those available in literature. In Fig. 11 the aerosol size segregated mass distributions in the ten cut-off size ranges are shown as a function of atmospheric humidity measured using a quartz crystal microbalance. It may be seen that there is an increase in the aerosol mass loading at the sub-micrometer region with an increase in $\mathrm{RH}$. Such an increase between the low to moderate increase in atmospheric humidity is by far more than the usual hygroscopic growth and resultant increase in the aerosol mass. Such an increase can result only by new particle formation. It may also be noted that the mass increase in the large particle mode is not that significant and resembles the usual hygroscopic growth. The growth at the mode is also limited by the aerosol removal by sedimentation. Thus, the QCM data also supports the proposed idea of new particle formation at the sub-micron region possibly by nucleation.

The aerosol optical properties as a function of the surface wind show that when the wind is from the NE direction, the aerosol spectral optical depths and size distributions show near background features with the presence of industrial particulate matter at the sub-micrometer region. However, during high wind speed conditions, the secondary mode seen at $0.8, \mu \mathrm{m}$ is also seen in the column integrated aerosol size distributions. This is due to the penetration of the marine air mass deep inland from the Bay of Bengal in the NE direction, giving rise to a mode at $0.8 \mu \mathrm{m}$, signifying the presence of the sea salt component brought in by the marine air mass. When the wind is from south or southwest, even during low wind conditions, the aerosol spectral features and optical depths show the presence of both the industrial and marine aerosols with a bi-modal distribution. During high wind speed conditions, the humid marine boundary layer penetrates inland over the industrial locations. During such conditions, new particle formation is favoured due to nucleation when the humid air mass brought in by the sea breeze interacts with the gas phase industrial product, as is observed during wet atmospheric conditions. These nascent particles then grow in the humid environment and show features similar to those observed during high humidity conditions. Thus, the size distributions at high humidity conditions and high S-SW conditions are similar, where a new particle mode at $0.4 \mu \mathrm{m}$ is seen. It is also possible that the industrial aerosols are transported onto the sea during land breeze conditions, become totally modified in the marine boundary layer and are brought on and during the sea breeze conditions, thus complicating the coastal urban aerosol system. The study indicates that quantifying the response of an aerosol system in a coastal urban environment as a function of surface weather is difficult due to the counter play of the effects of the different parameters such as wind and humidity during different conditions.

Acknowledgements. This work is supported by the Indian Space Research Organisation under ISRO-Geopshere Biosphere programme. The authors thank the Topical Editor O. Boucher and the other reviewer for their suggestions.

Topical Editor O. Boucher thanks S. K. Satheesh for his help in evaluating this paper.

\section{References}

Boucher, O. and Anderson, T. L.: General circulation model assessment of sensitivity of direct radiative forcing by anthropogenic sulfate aerosols to aerosol size and chemistry, J. Geophys. Res., 100, $26117-26134,1995$.

Clarke, A. D., Varner, J. L., Eisele, F., Mauldin, R. L. and Tanner, D.: Particle production in the remote marine atmosphere: cloud outflow and subsidence during ACE1, J. Geophys. Res., 103, 16397-16409, 1998.

Covert D. S., Kapustin, V. N., Quinn, P. K., and Bates, T. S.: New particle formation in the marine boundary layer, J. Geophys. Res., 97, 20 581-20 589, 1992.

Fitzerald J. W., Hoppel, W. A. and Victty, M. A.: The size and scattering coefficient of urban aerosol particles at Washington DC as a function of relative humidity, J. Atmos. Sci., 39, 1838-1852, 1982.

Grenfell, J. L., Harrison, R. M., Allen,A. G., Shi, J. P., Penkett, S. A., O’Dowd, C. D. Smith, M. H., Hill, M. K., Robertson, L., Hewitt, C. N., Davidson, B., Lewis, A. C., Creasey, D. J., Heard, D. E., Hebestreit, K., Alocke, B., and James, J.: An analysis of rapid increases in condensation nuclei concentrations at a remote coastal site in western Ireland, J. Geophys. Res., 104, $13771-$ $13780,1999$.

Gulyaev, Y. N., Yershov, O. A., and Shifrin, K. S.: The air mass influence on spectral transmittance in typical maritime regions (in Russian) in atmospheric and marine optics (Shifrin, K. S. ), 96-97, State Optical Institute, Leningrad, 1990.

Hegg, D. A., Covert, D. S., Rood, M. J. and Hobbs, P. V.: Measurements of aerosol optical properties in maritime air, J. Geophys. Res., 101, 12 893-12 903, 1996.

Holben B. N., Tanre, D., Smirnov, A., Eck, T. F., Slustsker, I., Abuhassan, N., Newcomb,W. W., Shafer, J. S., Chatenet, B., Lavenu, F., Kaufman, Y. K., Vande Castle, J., Setzer, S., Markham, B., Clark, D., Frouin, R., Halthore, R., Karneli, A., O’Neill, N. T., Pietras, C., Pinker, R. T., Voss, K., and Zibordi, G.: An emerging ground based aerosol climatology: Aerosol optical depth from AERONET, J. Geophys. Res., 106, D 11, 12 067-12 097, 2001.

Im, J., Saxena, V. K. and Wenny, B. N.: An assessment of hygroscopic growth factors for aerosols in the surface boundary layer for computing direct radiative forcing, J. Geophys. Res., 106, 20 213-20 224, 2001.

Jha, B. and Krishna Murthy, T. N.: Real time meteorological atlas during the INDOEX -1999, FSU rep. 99-09, Fla State Univ., Tallahassee, 1999

Kasten, F.: Visibility in the phase of pre-condensation, Tellus, 21, 631-635, 1969. Keen C. S. and Lyons, W. A.: Lake/land breeze circulations on the western shore of lake Michigan, J. Appl. Meteorology, 17, 1843-1855, 1978. 
Keen, C. S. and Lyons, W. A.: Lake/land breeze circulations on the western shore of lake Michigan, J. Appl. Met., 17, 1843-1855, 1978.

Khvorostyanov, V. I. and Curry, J. A.: A simple analytical model of aerosol properties with account for hygroscopic growth 2. Scattering and absorption coefficients, J. Geophys. Res., 104, 21632174, 1999.

King, M. D., Byrne, D. M., Herman, B. M., and Reagan, J. A.: Aerosol size distributions obtained by inversion of spectral optical depth measurements, J. Atmos. Sci., 35, 2153-2167, 1978.

King, M. D.: Sensitivity of constrained linear inversion to the selection of lagrange multiplier, J. Atmos. Sci., 39, 1356-1369, 1982

McGovern, F. M., Jennings, S. G., O'Connor, T.C. and Simmonds, P. G.: Aerosol and trace gas measurements during Mace Head Experiment, Atmos. Environ., 30, 3891-3902, 1996.

Michalsky, J. J., Schlemmer, J. A., Berkheiser, W. E., Berndt, J. L., Harrison, L. C., Laulainen, N. S., Larson, N. R. and Barnard, J. C.: Multiyear measurements of aerosol optical depth in the atmospheric radiation measurement and quantitative links programs, J. Geophys. Res., 106, D11, 12 099-12 107, 2001.

Moorthy, K. K., Satheesh, S. K., and Krishna Moorthy, B. V.: Investigations of marine aerosols over tropical indian ocean, J. Geophys. Res.,102, 18 827-18 842, 1997.

Moorthy, K. K., Saha, A., Prasad, B. S. N., Niranjan, K., and Jhurry, D.: Aerosol optical depths over peninsular india and adjoining oceans during the INDOEX CAMPAIGNS: spatial, temporal and spectral characteristics, J. Geophys. Res., 106, 28 539-28 554, 2001.

Nair, P. R. and Morrthy, K. K.: Effects of changes in the atmospheric water vapopur content on the physical properties of atmospheric aerosols as a coastal station, J. Atmos. Terr Phys., 60, 981, 1998.

Niranjan, K. and Ramesh Babu, Y.: Atmospheric water vapour and its effect on aerosol extinction at a coastal station, Visakhapatnam, Mausam, 44, 243-248, 1993.

Niranjan, K., Ramesh Babu, Y., Satyanarayana, G. V., and Thulasiraman, S.: Aerosol spectral optical dephs and typical size distributions at a coastal urban location in India, Tellus, 49B, 439-446, 1997.

Niranjan, K., Thulsairaman, S., Satyanarayana, G., and Ramesh Babu, Y.: Temporal characteristics of aerosol optical depths and size distribution at visakhapatnam, India, Aerosol Sci. Tech., 32, 283-292, 2000.
O'Dow, C. D. and Smith, M. H.: Physiochemical properties of aerosols over the northeast atlantic: Evidence for wind-speed related submicron sea salt aerosol production., J. Geophys. Res., 98, D1 1137-1149, 1993.

Parameswaran, K., Rekha Rajan, Vijayakumar, G., Rajeev, K., Moorthy, K. K., Nair, P. R. and Sateesh, S. K.: Seasonal and long term variations of aerosol content in the atmospheric mixing region at a tropical station on the arabian sea-coast, J. Atmos. Terr. Phys., 60, 17-25, 1998.

Pinker, R. T., Ferrare, R. A., Karnieli, A., Aro, T. O., Kaufman, Y. J., and Zangvil, A.: Aerosol optical depths in a semiarid region, J. Geophys. Res., 102, 11 123-11 137, 1997.

Raes, F., Wilson J., and Van Dingenen, R. : Aerosol dynamics and its implication for the global aerosol climatology, in:Aaerosol forcing of climate, ediited by Charlson, R. J. and Heintzenberg, J., John Wiley and Sons, New York NY: 153-169, 1995.

Satheesh, S. K. and Moorthy, K. K.: Atmospheric total ozone content from spectral extinction measurements, Ind. J. Radio and Space Phys., 25, 204, 1996.

Saxena, P., Hildemann, L. H., Mc. Murry, P. H. and Seinfeld, J. H.: Organics alter hygroscopic behaviour of atmospheric particles, J. Geophys. Res., 100, 18, 755-18 770, 1995.

Shettle, E. P. and Fenn, R. W.: Models of aerosols of the lower atmosphere and the effect of humidity variation on their optical properties, AFGL-TR-79-204, 1979.

Smirnov, A., Royer, A., O’Neill, N. T., and Tarussov, T.: A study of the link between synoptic air mass type and atmospheric optical parameters, J. Geophys. Res., 99, 20 967-20 982, 1994.

Smirnov, A., Villevalde, Y., O’Neill, N. T., Royer, A., and Tarussov, A.: Aerosol optical depth over the oceans: analysis in terms of synoptic air mass types, J. Geophys. Res., 100, D8, $16639-$ $16650,1995$.

Von Hoyningen Huene, W. and Raabe, A.: Continental and maritime air mass differences in optical aerosol extinction data, Beitr. Phys. Atmos. 60, 81-87, 1987.

Von Hoyningen Huene, W. and Wendisch, M.: Variability of aerosol optical parameters by advective processes, Atmos. Environ., 28, 923-933, 1994.

Weber, R. J., Mc. Murray, P. H., Mauldin III, L., Tanner, D. J., Eisele, F. L., Clarke, A. D. and Kapustin, V. N.: New particle formation in remote troposphere: a comparison of observations at various sites, Geophys. Res. Lett., 26, 307-310, 1999. 